\title{
Geneticist launches bid for US Senate
}

Michael Eisen hopes a victory in 2018 will bring a new scientific voice to the US legislature.

\section{Sara Reardon}

27 January 2017

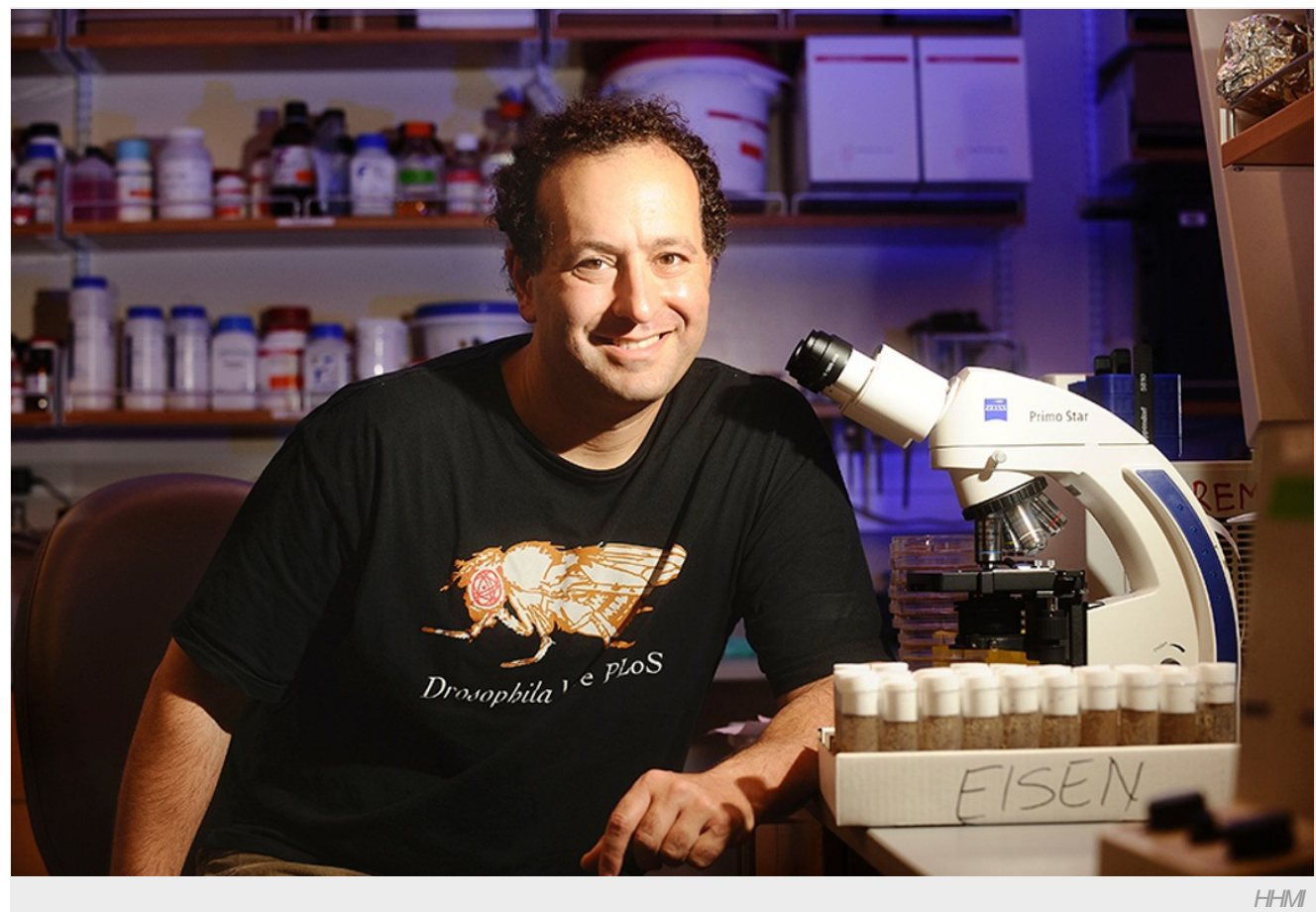

Michael Eisen hopes to win election to the US Senate in 2018.

In the week since President Donald Trump took the oath of office, scientists have taken to social media en masse, decrying the new administration's plan to dismantle climate regulations, reports that the administration has censored government scientists' speech and the coining of the term "alternative facts."

But Michael Eisen, a geneticist at the University of California, Berkeley, thinks that the situation requires more drastic action. So on 25 January, he announced on Twitter that he will run for US Senate in 2018.

Eisen, who is best known as an advocate for free access to scientific publications and as co-founder of the Public Library of Science (PLoS) journals, may have a viable path to elected office. Dianne Feinstein, the 83-year-old senator from his state, California, has indicated that she might not run for re-election in 2018.

Nature caught up with Eisen to ask him about his plans. This interview has been edited for length and clarity.

\section{What made you decide to run?}

This election, and in particular, everybody's worst fears about the new administration's attitudes. Not toward science in the narrow sense — I don't think people are worried about whether the NIH [National Institutes of Health] budget will go up or down by $2 \%$ - but the basic rejection of the fundamental principles upon which science is based.

I've long thought that there's been a dearth of scientific engagement with politics in general. Spouting on Twitter just feels inadequate. People are saying, "Where are all the senior scientists to stand up and defend science?". I just sort of felt like, they're right.

l'd never really thought about [running for office] in any serious way. I love my job. Doing something takes my focus away from my job — l've never wanted to do that before. But I feel like this moment calls for people to take some risks and do something. 
That's the place where the issues are in focus. I keep wanting to see a scientist in these hearings on all these presidential appointees, who can ask them questions that a scientist would ask. There are a few scientists in the House, but there aren't any in the Senate. It just seemed like a possible opportunity there if Feinstein doesn't run.

\section{Without any experience as an elected official, do you think you'd have a chance of winning?}

If you've learned anything from this election, it's that we're in a time where political outsiders are actually having some success.

California has an open primary, where the top two vote-getters go to the general [election]. Especially if Feinstein chooses not to run for re-election, who knows how many people will vie for the top two slots? There's an opportunity for a candidate that comes at things in a different way, and in a way that I think the people in California especially could appreciate.

\section{What's your platform?}

This is not about fighting for science funding: scientists feel like not just our voice, but our perspective is not well represented in politics. And because politicians have ignored or have been outright attacking science, so much of what we believe in is under threat. We're paying the price for having been politically disengaged for such a long time.

I think we've not tackled climate change in the right way. We need to recognize that climate change is not just some real phenomenon, it's a major crisis. My goal is not to go around shouting that you have to believe scientists, because that doesn't work. It's not trying to go to Paris and passing some sort of aspirational goals to cut back on emissions. We need to be looking at every aspect of our lives: how we produce food, how we produce fuel, how we travel around the planet, and asking fundamentally what things we can do right now to have a major impact.

Obviously the Senate is a complicated thing, with a lot of issues, and as we move forward, I will be speaking my mind. What l'm interested in is studying these things like a scientist and figuring out what's the right way to proceed.

\section{What's the next step for you?}

I have reached out to people with experience in politics to start figuring out what has to happen next. I'm surprised by how many people seem really into the idea. I think the fact that there's been so much support already on Twitter says something not about me, but about the desire amongst the broad science community to step up and get involved.

I'm on sabbatical this year. I'm going to take advantage of the fact that this semester I'm not teaching and am free to figure out if there's a path forward, and to use the fact that people are interested in this as a way to talk about the important political issues we are facing. This is not something we can afford to wait for.

Nature | doi:10.1038/nature.2017.21381 